\title{
Applied Behavior Analysis in Residential Settings: Use of a Mobile Application to Support Parental Engagement in At-Home Educational Activities
}

\author{
Isabela Zaine1, Priscila Benitez², Kamila Rios da Hora Rodrigues ${ }^{1,3}$, \\ Maria da Graça Campos Pimentel ${ }^{1}$ \\ ${ }^{1}$ Institute of Mathematics and Computer Sciences, University of São Paulo, São Carlos, Brazil \\ ${ }^{2}$ Center for Mathematics Computing and Cognition, Federal University of ABC, São Bernardo do Campo, Brazil \\ ${ }^{3}$ Federal University of São Carlos, São Carlos, Brazil \\ Email: isazaine@icmc.usp.br, priscila.benitez@ufabc.edu.br, kamila_rodrigues@dc.ufscar.br, mgp@usp.br
}

How to cite this paper: Zaine, I., Benitez, P., da Hora Rodrigues, K. R., \& da Graça Campos Pimentel, M. (2019). Applied Behavior Analysis in Residential Settings: Use of a Mobile Application to Support Parental Engagement in At-Home Educational Activities. Creative Education, 10, 1883-1903. https://doi.org/10.4236/ce.2019.108136

Received: July 5, 2019

Accepted: August 16, 2019

Published: August 19, 2019

Copyright $\odot 2019$ by author(s) and Scientific Research Publishing Inc. This work is licensed under the Creative Commons Attribution International License (CC BY 4.0).

http://creativecommons.org/licenses/by/4.0/

(c) (i) Open Access

\begin{abstract}
Parental involvement in interventions based on Applied Behavior Analysis for children with Autism Spectrum Disorder (ASD) is encouraged to increase learning opportunities at home. The use of technologies increases the extent of interventions that occur outside therapeutic settings. Thus, our main goals were: 1) to compare the effect of the use of a mobile application-ESPIM-on the frequency of conducting complementary educational activities by parents at home, to traditional strategies (verbal and written instructions); 2) to analyze the strategies used by the parents and the reliability of the performance registry; 3) to analyze the viability of adoption of a software solution as support for parents. Three families and their children with ASD participated. The results indicated that the use of the application proved to be effective to increase parental engagement in conducting the complementary educational activities at home with reliable registry. The technological support seemed to be a viable solution to increase parental engagement, as it was easily and readily adopted and as it was perceived by parents as useful.
\end{abstract}

\section{Keywords}

ABA, ESPIM, Complementary Educational Activities,

Home-Based Interventions, Mobile Application, Parents,

Autism Spectrum Disorder 


\section{Introduction}

The main behavioral characteristics of people with Autism Spectrum Disorder (ASD) are qualitative impairment in social interactions, communication and present restricted and repetitive patterns of behavior, interests or activities (APA, 2013). Individuals with ASD may present deficits and/or behavioral excess in different areas of development, such as language, social skills, self-care skills, motor skills and cognitive tasks (Bagaiolo et al., 2017).

Among the main therapeutic and educational approaches aimed at individuals with ASD, interventions based on Applied Behavior Analysis (ABA) present positive, replicable and evidence-based results for the acquisition basic behavioral and complex developmental repertoires (Bagaiolo et al., 2017; Cooper, Heron, \& Heward, 2007; Leach, 2014). ABA teaching practices are individualized, planned according to each individual's existing behavioral repertoires and aiming towards the acquisition of novel skills. These are assessed by the evaluation of the expected performance according to a behavioral checklist. The intervention is then guided by a personalized teaching curriculum that presents a detailed schedule of each behavioral goal (Kabout, Mais, \& Segal, 2003).

The first study that used the principles of Experimental Behavior Analysis to teach children with ASD was documented by Lovaas (1987). The participants were exposed to an intensive teaching schedule with 40 hours of activities per week. In this study, $47 \%$ of the children presented similar performances to the children without ASD. This study was the first to point out the importance of the high intensity of the intervention programs for the effectiveness of the intervention based on ABA.

However, the intensiveness of the intervention is not always accessible to some families of individuals with ASD due to practical and financial issues, such as difficulties in finding available services and qualified professionals to carry out the interventions and the high costs associated with these intensive interventions. An alternative to deal with this scenario is to involve parents and/or other family members in the intervention, training them to act as educational agents at home (Gomes et al., 2017).

This strategy has become increasingly more common and several research present encouraging results (Gomes et al., 2017; Guimarães, 2018; Jacobson, 2000; Johnson \& Hastings, 2002) and it has proven to improve the effectiveness of the intervention by increasing the intensity of the intervention and also by creating more opportunities for the generalization and for the maintenance of the acquired skills (Benitez \& Domeniconi, 2014; Gortmaker, Daly III, McCurdy, Persampieri, \& Hergenrader, 2007; Mcconachie et al., 2005).

Several studies aimed to investigate the impacts of the involvement of parents in the education process of their children with ASD. For example, Mcconachie et al. (2005), evaluated strategies of how to involve the parents of students with ASD in their children's education and how to facilitate the social communication between them. Others were dedicated to promoting language teaching through 
training the parents to start social interaction with their children with ASD (Girolametto, Sussman, \& Weitzman, 2007), and to lead parents to better understanding the school trajectory of their children with ASD (Benitez, Gomes, Bondioli, \& Domeniconi, 2017). Specifically regarding ABA-based intensive behavioral intervention, Gomes, Souza, Silveira and Oliveira (2017) aimed to evaluate the effects of parent involvement in the first year of intervention with their children with ASD with ages ranging from 15 to 35 months. The parents were trained to conduct educational activities organized in discrete trials and to register their children's performance. The weekly workload was of 15 hours. They reported positive outcomes in the development of the children exposed to the parent-led home intervention. Seemingly, Guimarães (2018) trained caregivers to manage inappropriate behavior emitted by their children with ASD using three procedures: video modeling, written instruction and role-play with immediate feedback. The results showed that the combination of the three strategies was effective in successfully managing the inappropriate behaviors.

Despite the importance and the benefits of parental involvement in ABA-based interventions, adherence and parental engagement do not always occur nor are satisfactory. Parental engagement is here defined as the extent to which the parents' behavior coincides with the recommendations of a professional (Allen \& Warzak, 2000). Even though studies evaluating the efficacy of ABA-based interventions are vast, investigation of the variables that affect parental engagement in such interventions are more scarce.

Moore and Symons (2009), for example, conducted a survey of 220 parents of children with ASD and found that adherence to behavioral treatments was significantly lower in comparison to adherence to medical treatments. In a subsequent study in 2011, the same authors investigated adherence to behavioral treatments for children with ASD based on six barriers perceived by parents exist relative to the behavioral strategies: 1) too difficult; 2) not effective; 3) limited support from family and friends; 4) belief that other clinical approaches would be more appropriate; 5) limited energy to be consistent; and 6) practices not aligned with family values. Among the main results, the authors reported that adherence was greater for those parents who perceived themselves as effective behavior modification agents, who believed that the intervention would produce benefits and who accepted their children in terms of limitations and potentialities among the family and in the community.

Several studies pointed out that ABA-based interventions demand availability of time, dedication and consistency from the staff and from the parents involved in order to achieve better results (e.g., Gomes et al., 2017; Guimarães, 2018; Lovaas, 1987; Sallows \& Graupner, 2005). These interfere in the parental engagement, sometimes leading to low adhesion to the behavioral intervention at home, which can be perceived by parents as a "burden" for the family (Anan et al., 2008). There are other variables that may hinder parental engagement in conducting the recommended activities at home, such as difficulties in following 
instructions, excessive skill complexity, weak management of the intervention environment, competing punitive contingencies to parents' behavior during the intervention (e.g., crying, temper tantrum), competing reinforcing contingencies to parents' behavior during the intervention, for example, resting or watching television (Allen \& Warzak, 2000).

One way to improve parental engagement in ABA-based interventions at home is through the use of technological resources that allow information exchange between parents and therapists and that allow some degree of monitoring of the activities to be conducted at home. Aligned to these goals, the computer system ESPIM-Experience Sampling and Programmed Intervention Method-is a software solution that offers alternatives for the remote data collection and the execution of interventions programmed by specialists from different domains of knowledge, such as education and health (Zaine et al., 2016).

The system allows a specialist, for example an educator or a therapist, to create personalized intervention programs. These intervention programs are executed through an application installed on the mobile devices (smartphones and tablets) of the target population. One of the features of the application is that it sends "reminders" so that participants engage on the programmed activities, by sending them visual and auditory notifications, scheduled by the specialist. The system also allows the exchange of different types of media between a specialist and the participants, such as text, image, audio and video (Rodrigues et al., 2017; Zaine et al., 2016). Through the use of the system it is possible to expand the scope of the data collection and the programmed set of interventions that can be remotely performed, in the participants' natural environment, without the presence of the researcher.

Regarding the importance of parental engagement in ABA-based interventions for children with ASD and the availability of a technological support, this study aimed to increase parental engagement in at-home complementary educational activities in ABA-based interventions for children with ASD using a software application-ESPIM. Our main goal was to compare the effect of introducing the variable "application" on the frequency in which parents conducted complementary educational activities at home, recording their children's performance in such activities, compared to traditional verbal instruction. A secondary goal was to analyze the interaction among parents and children during the interventions regarding the strategies used by the parents and the reliability of the performance record. Finally, a third goal was to analyze the viability of adoption of a software solution, such as the ESPIM system, as support for parents to conduct the educational activities at home. We consider that innovative solutions involving technology that somehow support parents to be more participative in conducting ABA-based activities at home provide children with more time of training and to more learning opportunities, ultimately fostering the children's development. These alternative and creative solutions are of special importance in low-income countries, such as Brazil, in which the costs of conducting ABA-based interventions with the appropriate weekly workload are still high, being less ac- 
cessible to a part of the population.

\section{Method}

\subsection{Participants}

The participants were three Brazilian parents of children with ASD with low engagement in conducting at-home ABA-based complementary educational activities. All children were students at a Brazilian non-governmental organization $(\mathrm{NGO})^{1}$ with a 2-hour/week workload. The NGO trained parents to conduct selected complementary educational activities ${ }^{2}$ at home and instructed them to do those daily, using a standardized data sheet to register performance. The three students were male and their parents were highly familiar with using smartphones and applications. The inclusion criteria were: 1) parental low engagement in conducting at-home complementary educational activities-frequency of 1 to 2 times a week for three consecutive months; 2) to own an Android smartphone or tablet; 3) internet access; 4) to allow the download of the ESPIM application on the mobile device. The behavioral/cognitive repertoire of the students with ASD was accessed by the VB-MAPP_Verbal Behavior Milestones Assessment and Placement Program (Sundberg, 2008). Table 1 presents each family's demographic information.

\subsection{Location and Materials}

The complementary educational activities were conducted by the parents at home and the data on the frequency of execution was automatically collected by the ESPIM application. The material was: the parents' personal Android smartphones with the ESPIM application and a performance data sheet. All the parents had already been trained by the professionals from the NGO on how to fill-in the performance data sheet, although they received new training before the beginning of this study. The parents also responded to a pre-and post-trial semi-structured interviews. The pre-trial interview presented two queries about

Table 1. Participants' demographic profiles.

\begin{tabular}{cccccccccccc}
\hline \multicolumn{1}{c}{ Student with ASD } & & & Parents \\
\hline & Age & 1 & 2 & 3 & 4 & 5 & 6 & $\begin{array}{c}\text { Main home } \\
\text { educational agent }\end{array}$ & Age & Educational level & Profession \\
Fam1 & $3 \mathrm{y}$ & 40 & 20 & 20 & 0 & 0 & 0 & Father & $38 \mathrm{y}$ & Graduate & Administrative technician \\
Fam2 & $6 y 6 \mathrm{~m}$ & 50 & 0 & 60 & 0 & 0 & 0 & Mother & $38 \mathrm{y}$ & Undergraduate & Finance assistant \\
Fam3 & $8 \mathrm{y} 2 \mathrm{~m}$ & 100 & 100 & 80 & 90 & 0 & 0 & Mother & $46 \mathrm{y}$ & Graduate & Educational coordinator \\
\hline
\end{tabular}

Note: The numbers 1 to 6 under "Performance-VB-MAPP” (Sundberg, 2008), refer respectively to motor imitation level 1; echoic level 1 (repeating words); listener response level 1 (identification of objects/pictures); 4 tact level 1 (naming objects/pictures); intraverbal level 2 (e.g., answering questions and completing phrases), 6 tact level 2 (naming objects/pictures).

${ }^{1}$ The study was approved by the Committee of Ethics in Research with Humans from the School of Arts, Science and Humanities-EACH/USP (\#57875016.3.0000.5390).

${ }^{2}$ It is important to highlight that the complementary activities were not intended to substitute any ongoing educational, behavioral or medical interventions. 
the frequency that they conducted at-home complementary educational activities and about their main difficulties in doing so. The post-trial interview was comprised of eight questions about: 1) Frequency of execution of at-home complementary educational activities; 2) Inclusion of other people while conducting the activities; 3) Advantages and difficulties in the use of the application; 4) A user experience and usability questionnaire.

\subsection{Variables and Design}

The independent variable was the introduction of the ESPIM application as a support for parents to conduct the at-home ABA-based complementary educational activities. The design was the A-B type: A-baseline; B-intervention. During baseline, for three weeks the families received verbal and written instructions to daily conduct at least one of three educational activities at home and to register their children's performance using a performance data sheet. This was the general strategy of the NGO, which we will refer to in this paper as "traditional'. It is important to remember that these parents were selected to participate in the study because they already presented low engagement in the at-home activities for three consecutive months prior to the study. The parents were also encouraged to video record the activities for future feedback. On condition B, the parents received through the ESPIM application notifications that functioned as reminders to conduct the activities daily, as well as instructions on how to proceed in each activity. The parents also registered their children's performance on the application. This condition lasted from 3 to 4 weeks. Thus, on condition $\mathrm{A}$, the application was not used and on condition $\mathrm{B}$, the application was used.

The dependent variables were the parental engagement in conducting the recommended activities and the registry of the children's performance on each activity. The parental engagement was measured by the number of times that the parents conducted the educational activities at home relying on the traditional strategy (condition A) or on the use of the application. Even though the children's performance was also collected, an analysis of the progression of the children's performance was not a goal of this study, once reliable data on learning would require the experiment to be carried out for a longer period of time.

\subsection{Procedure}

The parents were instructed to conduct at least one out of three planned educational activities at home with their children, once a day, for six consecutive weeks. The activities were selected by the professionals of the NGO and corresponded to relevant skills in phases of acquisition or maintenance, according to each student's individualized teaching curriculum based on their assessment on the VB-MAPP. Table 2 presents the activities selected for each student of the participant families.

The parents underwent through two different conditions: Baseline-condition 
Table 2. Description of the activities selected for each student of the participant families.

\begin{tabular}{|c|c|c|c|c|}
\hline Family & Activity & Phase & Description & VB-MAPP \\
\hline \multirow{3}{*}{ Fam 1} & A1. Blow & Acquisition & Adult models blowing (with or without objects): "Do this (blows)" & Motor imitation-Level 1 \\
\hline & A2. Wave good-bye & Acquisition & Adult presents the verbal instruction: "Wave good-bye". & Listener-Level 1 \\
\hline & A3. Repeat "woof-woof" & Acquisition & Adult presents verbal model: "Say 'woof-woof” & Echoic-Level 1 \\
\hline \multirow{3}{*}{ Fam 2} & A1. Stick tongue out & Acquisition & Adult models sticking tongue out: "Do this (sticks tongue out)" & Motor imitation-Level 1 \\
\hline & $\begin{array}{l}\text { A2. Bang hands on table } \\
\text { and clapping hands }\end{array}$ & Maintenance & $\begin{array}{l}\text { Adult models banging hands on table and clapping hands in } \\
\text { sequence: "Do this (bangs on table and claps hands)" }\end{array}$ & Motor imitation-Level 1 \\
\hline & A3. Point to objects & Acquisition & $\begin{array}{l}\text { Adult positions familiar objects near the child and asks him/her to } \\
\text { point to the named objects: "Point to (...)" }\end{array}$ & Listener-Level 1 \\
\hline \multirow{3}{*}{ Fam 3} & A1. Enumerate categories & Maintenance & Adult presents the instructions: "Say things that grow on trees" & Tact-Level 2 \\
\hline & A2. Rhyme & Acquisition & Adult presents the instructions:"Say words that rhyme with (...)" & Tact-Level 2 \\
\hline & A3. Answer question & Maintenance & Adult asks the question: "What is your full name?" & Intraverbal-Level 2 \\
\hline
\end{tabular}

A-and Application-condition B. On the first three weeks, they relied on the traditional strategy and on the last three, on the application. All parents were trained to conduct and to register the performance on all the three required activities: they observed a professional from the NGO conduct the activities with the children and then they conducted a couple of trials under the professional's supervision.

During the baseline, the parents were provided with a performance data sheet that presented three different educational activities and written instructions on how to conduct them. They were encouraged to conduct at least one of them on a daily basis for three consecutive weeks. On condition B the parents received the same instructions and the performance data sheet, with the difference that the application was introduced to foster parental engagement as it follows: on week 1 the application requested the activity 1 ; on week 2, the activity 2 ; and on week 3 -the activity three. Even though the application requested only one activity per week, as in the baseline condition, they were encouraged to conduct one or more activities per day, as in the baseline condition. Furthermore, requesting only one activity at a time through the application could demonstrate if the parental engagement would be generalized and extended to the other activities. For example, if the parents conducted the activity 1 requested through the application, they could take advantage of the training situation and also conduct activities 2 and 3, registering the performance on the data sheet.

The educational activities were different on condition A and B, though they were comparable in terms of difficulty, according to the VB-MAPP assessment. The activities were different for each student, once the ABA-based intervention is personalized according to each individual's behavioral goals.

An example of the flow of events and screens presented by the application are shown in Figure 1. It basically consisted of: 1) Receive of a notification as a reminder; 2) Presentation of the instructions identical to the instructions on the performance data sheet and/or a video-model (10 s) of how the activity should 


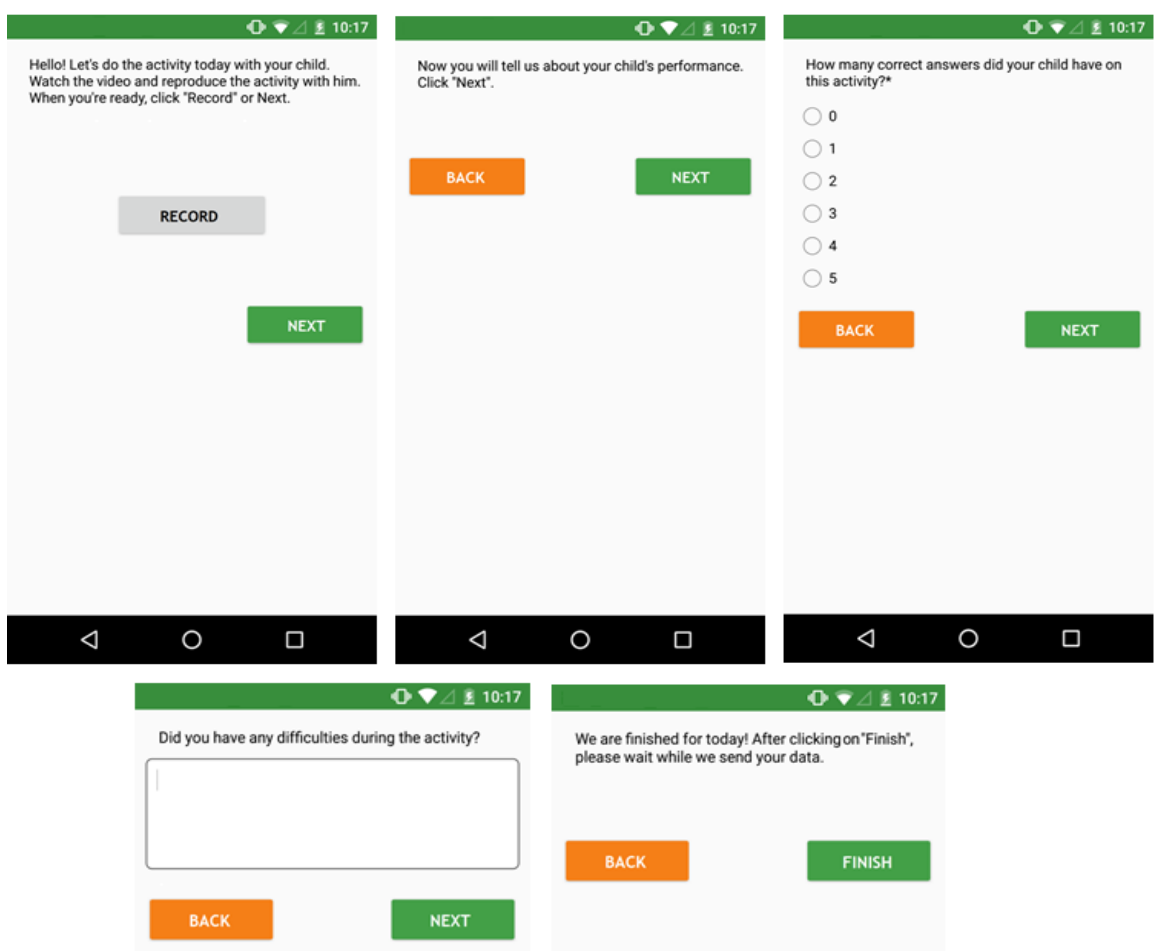

Figure 1. Example of the flow of events and screens presented by the application as depicted on the smartphone. Note: The original language of the application interface and text was Brazilian Portuguese, which is the participants' native language.

be performed; 3) Requisition to video-record the activity (optional); 4) Performance registry; 5) Description of their main difficulties through a text entry (when applicable).

Video-recording the activity was optional so that the situation would better correspond with the "traditional" instructions, in which the professionals of the NGO encouraged the parents to record the activity when possible, also to avoid that parents would not engage in the activities due to practical difficulties in recording or privacy concerns. In every activity request, the first interaction of the parents with the application was to read the instructions of how to carry on an activity and/or to watch an instructional video. Watching the video was a mandatory request only for the first time that a certain activity was requested and it could be skipped in the subsequent requests. The video depicted the therapists video-modeling how to conduct the activity. In sequence, the application gave 
the parents the option to video-record the activity. If they agreed with it, the application automatically started the camera. If they preferred not to record, the application showed a screen similar to the data recording sheet, so that they could register the children's performances. Finally, the application presented parents with an open-ended question ("Did you have any difficulties during the activity?") for them to register their main difficulties, if any, while conducting the activity. To finalize the interaction, the application presented a feedback message and sent the data to the server. The daily notifications that served as reminders were scheduled according to each family's preferences and were automatically triggered by the application. In the case that the parents could not do the activity in the scheduled moments, that could perform it in a more convenient time by self-initiating the application.

After the six-week trial, each family participated in an individual semi-structured interview and responded to a user experience questionnaire. In these opportunities, they also received feedback over their interaction with their children while conducting the activities and their main perceived difficulties.

\section{Results}

In this section, the results are presented in terms of: 1) Parental pre-experimental non-compliance to the at-home ABA-based educational activities; 2) Parental engagement in conducting the activities; 3 ) Reliability of parental performance registry; 4) Strategies used by the parents during the activities; and 5) Experience of use of the application.

The pre-experimental non-compliance data was collected at the pre-trial semi-structured interviews and corresponded to the motives perceived by parents that interfered with their commitment to conduct the at-home ABA-based educational activities. The parental engagement was measured by the number of times the parents conducted the selected at-home ABA-based educational activities with their children prior and after the application was introduced. The data was analyzed using nonparametric statistical tests due to the properties of the sample. We used the Wilcoxon signed-rank test for related samples related to assess potential differences in the parental engagement before and after the application was introduced (baseline vs. application). The Kruskal-Wallis test for independent samples was used to compare parental engagement across activities. All tests were two-tailed with a level of significance of $p<0.05$.

The parental registry reliability was assessed by the accuracy of the correspondence between registries of what parents judged as correct or incorrect responses to the actual responses given by the children. For this, three judge's specialists in Applied Behavior Analysis conducted a blind evaluation of the videos recorded by the parents. The strategies used by the parents were also assessed by the video recordings and were qualitatively analyzed. Finally, the experience of use of the application was analyzed based on the parents' responses to the User Experience Questionnaire and additional information provided on the post-trial 
interview. This analysis was important to evaluate the viability of including a technological solution such as the ESPIM application to the practices related to enhancing and monitoring parental engagement in at-home complementary educational activities based on ABA to children with TEA.

\subsection{Parental Pre-Experimental Non-Compliance to the At-Home ABA-Based Educational Activities}

In the pre-trial interviews, all families admitted that they rarely conducted the at-home activities as instructed by the professionals of the NGO. They considered that performing the educational activities in a more structured way and registering the children's performance was high demanding and that they often did not have the time or the energy to do so after a day of work. They also mentioned having difficulties managing some of the children's "misbehavior", such as crying and temper tantrums, which led to a lack of motivation to even try to conduct the activities at home. The family, for example, reported: "We know that it is important to practice at home (...) but we come home tired and we know that he is going to be a handful that he will cry and throw a tantrum".

Two of the families (2 and 3) also considered that the lack of support from other people to conduct the at-home activities, especially other family members, was a problem that hindered their engagement. In the case of this study, for both families the mother was the main career and the one responsible to conduct the educational activities and they reported feeling overloaded, as reported by the mother from family 3: "I have no support. It's always on me to conduct the activities, so I feel tired".

Another challenge perceived by a couple of families (families 1 and 2), was to feel insecure to conduct the activities at home without direct professional supervision. They reported to be afraid of incorrectly conducting the activities, which could jeopardize their children's learning process. For example, family 2 reported: "Even though I watch the professionals at the NGO do the activities (...) I am afraid of doing it wrong (...) I am always insecure that if I do it wrong I will impair his learning".

Finally, all the families mentioned that they perceive a behavioral and performance discrepancy between the activities conducted at the NGO and at home. They considered that the children were more cooperative at the NGO and also presented a better performance when compared to the activities conducted at home. For example, family 1 reported: "I see him doing everything at the NGO (...) he stays seated and keeps quiet. Then, when he comes home I can't even get him to seat to start”.

\subsection{Parental Engagement in Conducting the At-Home ABA-Based Activities}

The data collected on the number of times the parents conducted the complementary educational activities at home show that there was a substantial increase after the introduction of the application. Figure 2 presents the number of sessions 


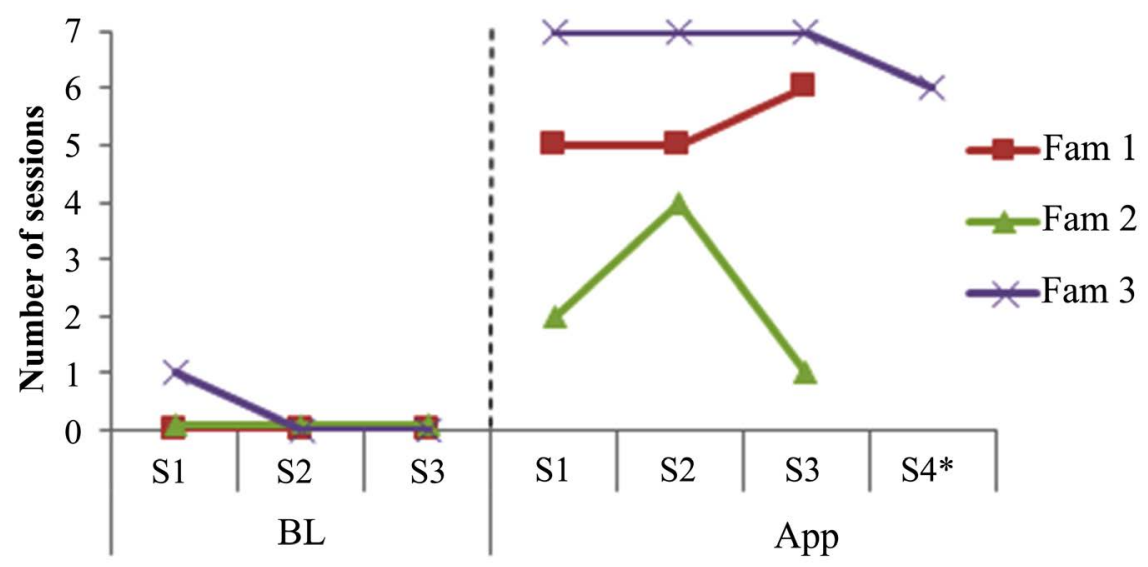

Figure 2. Number of sessions conducted by the parents of each family during the Baseline (BL) and Application (App) conditions. ${ }^{*}$ Family 3 requested to use the application for an extra week to re-do Activity.

conducted by the parents of each family during the Baseline (BL) and Application (App) conditions. It can be observed that during the three weeks of baseline, two of the families ( 2 and 3 ) did not conduct any of the activities and one family (family 3 ) conducted only one session in the entire period. Although, after they started using the application, there was a significant increase in the number of sessions conducted by the parents for all the families: the number of sessions conducted increased from zero or one per week to an average of five sessions per week. The Wilcoxon test indicated that the number of sessions conducted by the parents at home in the baseline and in the application conditions significantly differed, being significantly superior after the application was introduced $(\mathrm{Z}=$ $-2.80, p<0.01$ ).

Despite the general increase in the number of sessions conducted for all families, there was some variability. Families 1 and 3 conducted between 5 to 7 sessions per week, with an average of 5.3 and 6.7 sessions per week, respectively. Family 2 presented slightly inferior results, conducting from 1 to 4 sessions per week, with an average of 2.3 sessions per week.

Figure 3 presents the frequency that each family conducted the activities week by week after the application was introduced. It can be observed that all the families conducted at least once each one of the selected activities at home. The mean frequency that each activity was conducted was similar to one another: 4.66 times for Activities 1 and 3, and 5.66 times for Activity 2. The Kruskal-Wallis test did not indicate any significant differences between the number of conducted sessions between activities $(\mathrm{H}=0.16, p=0.92)$ indicating that the activities were comparable in terms of difficulty, as it was planned by the professionals from the NGO.

Even though the parents were instructed that they could conduct all of the selected activities in a daily basis, it can be observed that in most cases the parents only conducted the activity that was requested by the application. The only exception was Family 3, in which case the mother also conducted the Activity 2 


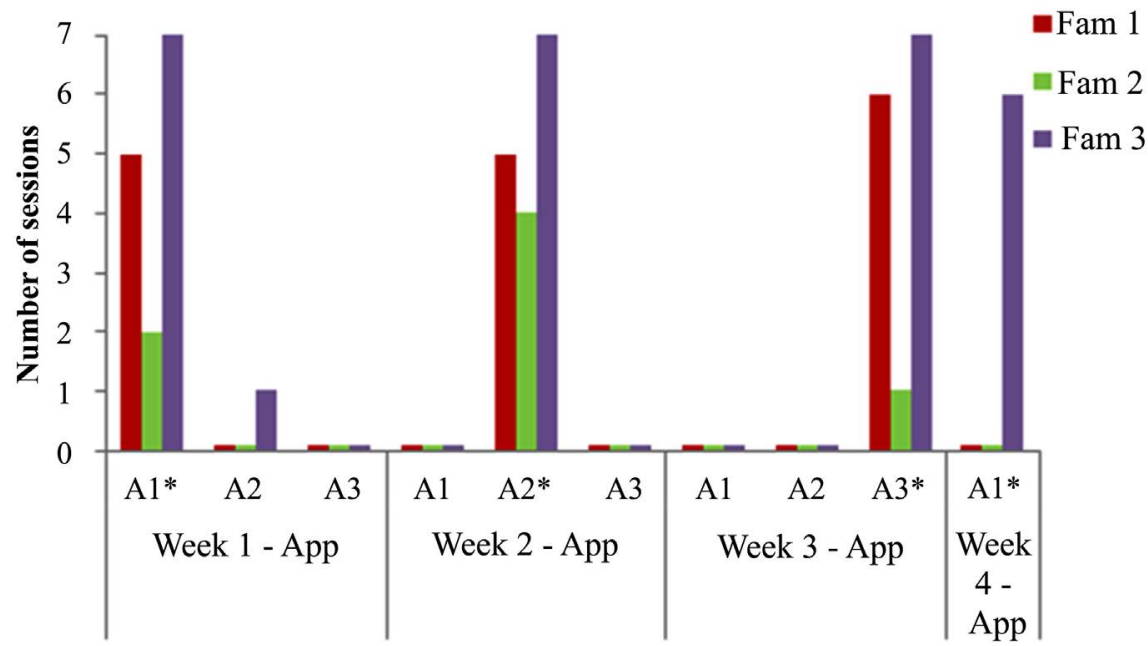

Figure 3. Weekly frequency that each family conducted the activities after the application was introduced. ${ }^{*}$ indicates which activity was requested by the application during each week.

once during Week 1 of use of the application (and in this case, on Week 1 the application requested the Activity 1). In all other cases the activities conducted were restricted to the ones requested by the application each week.

\subsection{Reliability of Parental Performance Registry}

We analyzed 11 videos that parents recorded. No videos were sent on the baseline condition, thus all the videos corresponded to the Application condition. From these, six videos were sent by Family 1, four from Family 2 and one from Family 3. As each session required parents to conduct five discrete trials for the activity to be considered concluded, a total of 55 trials were analyzed.

There was a correspondence of the performance observed by the judges in the videos and the performance registered by the parents in all of the trials for Families 2 and 3. For Family 1, there was a correspondence between five out of the six videos and the only divergence was that the parents registered one correct response as incorrect. Thus, in this sample of videos the parents correctly registered the performance in $92.7 \%$ of the trials with $100 \%$ of agreement between judges.

\subsection{Strategies Used by the Parents during the At-Home ABA-Based Activities}

The parents presented high behavioral variability and used several strategies to engage their children in doing the educational activities at home. They tried to conduct the activities in a playful way and alternated between the educational activities and other activities with higher reinforcing value to the children, in order to maintain their engagement and interest in the situation. Among the observed strategies that produced positive results were: 1) the use of objects as reinforcing stimuli; 2) the use of food as reinforcing stimuli; 3 ) the use of social 
consequences as reinforcing stimuli; 4) varying the location in which the activities were conducted; 5) involving other family members in the activity.

For example, the Family 1 used several external objects to stimulate the child in the blowing imitation activity. In the session that there were a higher number of correct responses, the parents used a piece of paper that moved when they blew into it. The movement was highly reinforcing to the child that smiled and clapped hands while imitating the parent. Family 2 used chocolate as a reinforce to the activity of motor imitation. All the families used social consequences as potential reinforces in case of correct answers (e.g. saying "Well done!", “Awesome" and clapping hands) and in most cases the children also celebrated their successes.

All the families varied among different locations to conduct the activities at home, varying among more structured settings, such as a desk, and less structured settings, such as the floor, a couch or bed. This variation did not disrupt the children's compliance to the activities nor their performance. In fact, it is possible that conducting the activities in less structured settings that are not so associated with the educational demands, may facilitate compliance and the generalization of target behaviors. They all also included other family members in the activities. The variation of people that help to conduct the activities is also desirable and favors generalization of the learned behaviors, such as the variation of the location. In the case of Family 1, the father and mother conducted the activities; in Family 3, the mother and younger brother were involved. In both cases the performance and compliance of the children were not disrupted. In the case of Family 2, on one occasion, the mother also involved three other family members (all adults) to conduct one activity. The situation, though was disorganized, with all of the adults interacting and making concomitant demands, which lead to a disruption of the child's responses. In this case, it is recommended that only one person interacts with the child at a time.

\subsection{Experience of Use of the Application}

To evaluate the viability of the use of the ESPIM system to support parental engagement in ABA-based complimentary at-home educational activities, besides analyzing the number of sessions conducted by the parents, we also collected data about their experience of use of the application in the post-trial interviews. The main characteristics pointed out by the families as positive were: 1) the notifications sent by the application; 2) the increase of the frequency of activities conducted at home; 3 ) the functionality of receiving and sending videos by the application; 4) the registry of their main difficulties immediately after conducting an activity.

All families considered the notifications a positive feature of the application as they served as daily reminders to conduct the activities, and that the reminders also motivated them to conduct the activities. For example, Family 1 reported: "Without the reminders we end up forgetting to do the activities or we surrender 
to tiredness (...). But when we heard the notification, we felt more motivated (...) we knew that we had to do the activity (...) that that was the time we reserved for that".

Regarding the frequency that they conducted the activities, all the families realized that they engaged more in them after they started using the application and considered that this extra training at home was important to improve their children's performance overall. Furthermore, the Family 1 reported that conducting more activities at home with their child made them more aware of the child's improvements: "In one day, he didn't do much, then on the other day he gave a lot of correct answers and on the following as well (...) it felt really good to see him progress in such a short time (..). The application helped us to commit in doing the activities more often and this helped him to improve".

The families also found useful that the application automatically received and sent videos and that by the end of every activity they could write their main difficulties that were also automatically sent by the application. They reported that receiving the video-models helped them to feel more confident and to reproduce the activities as recommended. They also appreciated that they could record and send the video-recordings of the activities conducted at home to the professionals for feedback. Even though previous to the use of the ESPIM application the parents were encouraged to send videos using other communication systems, such as WhatsApp or e-mail, the families reported that they usually did not do this because they either forgot and/or they considered inconvenient to record and then send the video as an attachment using other communication systems, resulting in many steps that should be taken separately. On the other hand, the ESPIM application automatically guided the parents through all of these steps without having to use several different applications. Regarding the registry of the parents' difficulties, although they were verbally encouraged to report them to the professionals of the NGO, once they rarely engaged in doing the activities at home, their reports, as described by the professionals of the NGO, or more related to general disruptive behavior than to specific behaviors related to the educational activities. The fact that every activity request was finalized with a query about their main difficulties encouraged parents to be more specific leading to better feedback from the professionals from the NGO.

Finally, all the families considered the application easy to use, they would use it frequently, they would continue to use it to conduct novel educational activities with their children at home, they judged the solution as useful, novel and creative and would recommend the use of the application for the purpose of increasing parental engagement in at-home ABA-based complementary educational activities.

\section{Discussion}

The main goal of this study was to analyze the effect of introducing the use of the ESPIM application on the frequency in which parents conducted ABA-based 
complementary educational activities at home with their children with ASD, compared to traditional verbal instruction. The parental engagement was measured by the frequency that parents conducted the recommended complementary educational activities at home using a novel technological application-ESPIM-to support their practice.

The results indicated that the use of the application increased the number of times that parents conducted the complementary educational activities with their children at home. The frequency that parents conducted the educational activities at home increased from null or nearly null to an average of five times per week after the use of the application was introduced. The parents also successfully registered their children's performance. Thus, the introduction of the application favored parental engagement in conducting the selected educational activities compared to the baseline data, a condition in which parents relied on verbal and written instructions of the activities and a data sheet to record performance. This data corroborates the results of other studies that aimed at training of family members to conduct complementary educational interventions at home (Benitez \& Domeniconi, 2014; Girolametto et al., 2007; Gomes et al., 2017; Gortmaker et al., 2007; Guimarães, 2018; Mcconachie et al., 2005).

Besides the increase in the number of at-home activities conducted by the parents immediately after the use of the application was introduced, the frequency remained high until the end of the study. This is possibly a combined product of certain variables such as the novelty of the application and the possibility for parents to actually notice their children's improvement in performance day-by-day. These may have increased the parents' tolerance to frustrations due to difficulties especially associated with the children's resistance to participate in the educational activities at home. Behaviors associated with "temper tantrums" discourage parents to conduct at-home educational activities (Anan et al., 2008) and may lead to low parental engagement. In our study, the parents reported some difficulties of managing their children's behaviors, such as crying, whining and throwing a tantrum. However, these reports consistently decreased throughout the study. Thus, it could be discussed that parents become more tolerant towards these disruptive behaviors and developed more efficient strategies to get their children involved in the educational activities. Furthermore, the parents also reported to in the post-test interview that they felt more confident in conducting the at-home activities across the experiment. All of these outcomes are likely to be reinforcing to parents and, as a consequence, may lead to higher and consistent engagement in the conduction of the at-home educational activities.

The parents' reports in the post-test interviews indicated some features of the use of the application that they considered the most relevant to the increase in their engagement in the educational activities at home such as: 1) Receiving daily notifications that served as reminders; 2) Receiving text or video instructions; 3) The possibility of video-recording the activities that were automatically sent to the researchers, which allowed feedback on parents' performance; 4) The possi- 
bility of registering their children's performance through the number of correct answers; 5) The possibility of registering their main difficulties faced while conducting the activities at home. With all these features combined, the use of the application also favored access not only to the children' performance, but also to the parents' and to the behavioral management strategies used by them. All of this information is extremely relevant for the education professionals to make better decisions while putting together the personalized teaching curricula. However, when the execution of the activities at home is encouraged exclusively through verbal and written instructions, such as in the baseline phase in this study, it is common that these data either "lost", as is the case of parents who do not turn in the performance data sheets, or that the information is vague relying on parents' verbal reports rather than the accurate performance registering.

Furthermore, a higher parental engagement conducting the complementary educational activities at home contributes not only to increasing the total amount of training opportunities to the children, but also to the process of generalization of the learned skills, broadening the students' behavioral repertoire. The teaching conditions and the home are not nearly as structured as the teaching environments at the formal educational institutions, although, if the learning procedures favor generalization it can be expected the student to successfully respond despite the physical location or people conducting the educational activity. Varying to some extent the people involved in a behavioral training as well as the environmental setting and stimuli is a desirable strategy to increase the chances of generalization of learned skills, which can avoid restricted stimulus control (Cooper et al., 2007; Lovaas, 1987; Foxx, 2008).

In addition to the use of the application have directly resulted in an increase in the number of activities carried out by the parents at home, which was the main goal of this study, the use of the application also had an effect in other difficulties faced and perceived by the parents, such as forgetfulness, lack of support from other family members, and fear of incorrectly conducting the activities. In the first case, the application's daily notifications, which served as a reminder that an activity should be conducted, helped the families to include the at-home educational activities as a part of their daily routines. In the second case, the use of the application favored the support of other people for conducting the activities, making the other relatives curious about the application and the activities. They offered to participate in some occasions, assisting both in video-recording and in the execution of the activities per se. In the last case, the parents reported to feel more confident as they received video-models of the activities, thus reproducing the educational activity more accurately similar to the professionals of the NGO. Also, as they were able to send videos of themselves while conducting the activities, they felt less insecure of "doing something wrong", as if that was the case the professionals could comment on their performance and give additional instructions.

A secondary goal of this study was to analyze the interaction between parents 
and children during the interventions regarding the strategies used by the parents and the reliability of the performance registering. The parents presented high behavioral variability to stimulate their children's participation in the activities, such as using objects and food items, using social consequences as reinforcers (e.g. praising, clapping hands) and including other family members in the activities. In most cases such strategies were successful. In the few cases in which the strategies led to negative results, the families received a detailed feedback on the reasons why the outcome was not positive and on how to proceed on future occasions. We consider that the possibility of providing more accurate feedback to parents may stimulate a more socially skillful parent-child interaction.

The video-records also allowed an evaluation the reliability of the data on the children's as registered by the parents. There was a correspondence of approximately $92.7 \%$ between the performance registered by the parents and the performance evaluated by ABA experts. Thus, it could be inferred by the sampled videos that the parents accurately distinguished between correct and incorrect responses, being able to emit the appropriate differential consequences to each, which is vital to behavioral interventions (Vollmer, Roane, Ringdahl, \& Marcus, 1999). Thus, we consider that this strategy should be encouraged whenever possible in ABA-based at-home interventions.

Despite the increase in the number of activities performed at home and the high adherence to the use of the application by the parents, they almost exclusively conducted the activities requested through the application, even though they were instructed that they could perform all of the activities in a daily basis. One could expect parents to take advantage of their children's compliance in one activity to perform the other two that were planned. Although, the parents reported in the final interview that they did not conduct than one activity per day due to difficulties in keeping their children's interest for longer periods of time. This might be a parents' difficulty associated to disruptive behavior management difficulties and not due to the children's "lack of interest", once these were used to performing educational activities at the NGO for up to 2 hours straight. It is possible that if the use of the application was maintained for a longer period of time the parents would become more competent in managing their children's behavior and, therefore, being able to conduct more than one activity at once.

Regarding the length of use of the application ( 3 or 4 weeks) it is possible, however, that the results were influenced by this reduced time window. All the three participating families maintained their commitment to perform the activities from the beginning to the end of the trial, with some variation in frequency. However, it is not known whether such initial adherence would continue in case the trial was extended. In future studies, it will be important to investigate the effects of the use of the application over time and habituation effects to the application, which could decrease engagement.

Finally, it is important to highlight the positive user experience over the ap- 
plication reported by the participants and the perceived usefulness of the application. In this study, the parents readily adopted the application and evaluated their experience while interacting with the application as positive, corroborating with research that present that positive user experience when interacting with new technologies (e.g. applications, devices) can lead to increased adherence to them (Norman, 1988). In addition, the parents also considered the application to be useful to achieve their goals in conducting the educational activities at home. The fact that users consider a technological solution to be of real value to their lives also enhances its adoption (Davis, 1989; Nielsen, 1993, 1994). Even though the number of participants was reduced in our study it can be expected that these results would be replicated with other participants with similar history of persistent low engagement in conducting at-home ABA based educational activities precisely because of the reported positive user experience and perceived usefulness of the use of the application. It is important to remember that before this study was conducted, the professionals of the NGO encouraged the parents to conduct the home activities using different communication technology solutions to register the home sessions, such as WhatsApp and e-mail. Although, those solutions did not increase the parents' engagement, whereas the use of the ESPIM application did.

The results obtained from the present study strengthen the discussion of the effects of at-home behavioral intervention conducted by parents and advance on the study of parental involvement in such activities, corroborating results from previous studies (Benitez \& Domeniconi, 2014; Gomes et al., 2017; Guimarães, 2018). The data here presented are optimistic about the viability of using creative solutions, such as the ESPIM system, to increase parental engagement in at-home ABA-based activities for children with ASD. It is extremely relevant in this context to constantly create novel alternatives, procedures and solutions to encourage and to support parents to be more participative in conducting ABA-based activities at home with their children as well as feeling more confident to perform themselves the recommended activities. This increases the children's learning opportunities and favors their development. Furthermore, if parents perceive themselves as competent and prepared to conduct the complementary educational activities at home, this task can be perceived as motivating, instead of burdensome, as the parents can actually perceive their children's progress closely, one day after the other, and playing a direct role in this process. Finally, engaging parents in conducting these activities at home themselves leads to an increase in the weekly workload without imposing additional financial expenses, making the behavioral intervention more accessible.

Based on these encouraging results, the same research group is now designing studies using the ESPIM system in order to overcome some limitations, such as reduced number of participants and novelty effects of the use of the application. We believe that extending the length of use of the application may help answering some of these questions, as well as allowing the investigation of the effects of 
parental engagement in at-home complementary educational activities on the children's learning, which can only be measured over time.

\section{Acknowledgements}

We thank NGO professionals and volunteer parents who participated in the studies. We also thank the Brazilian research fomenting agencies FAPESP-São Paulo Research Foundation (grant\#2015/18117-7) and CNPq for financial support.

\section{Conflicts of Interest}

The authors declare no conflicts of interest regarding the publication of this paper.

\section{References}

Allen, K. D., \& Warzak, W. J. (2000). The Problem of Parental Nonadherence in Clinical Behavior Analysis: Effective Treatment Is Not Enough. Journal of Applied Behavior Analysis, 33, 373-391. https://doi.org/10.1901/jaba.2000.33-373

American Psychological Association APA (2013). Diagnostic and Statistical Manual of Mental Disorders (5th ed.). Porto Alegre: Artes Médicas. (In Portuguese) http://www.tdahmente.com/wp-content/uploads/2018/08/Manual-Diagn\%C3\%B3stico -e-Estat\%C3\%ADstico-de-Transtornos-Mentais-DSM-5.pdf https://doi.org/10.1176/appi.books.9780890425596

Anan, R. M., Warner, L. J., McGillivary, J. E., Chong, I. M., \& Hines, S. J. (2008). Group Intensive Family Training (GIFT) for Preschoolers with Autism Spectrum Disorders. Behavioral Interventions: Theory \& Practice in Residential \& Community-Based Clinical Programs, 23, 165-180. https://doi.org/10.1002/bin.262

Bagaiolo, L. F., Mari, J. J., Bordini, D., Ribeiro, T. C., Martone, M. C. C., Caetano, S. C., Brunoni, D., Brentani, H., \& Paula, C. S. (2017). Procedures and Compliance of a Video Modeling Applied Behavior Analysis Intervention for Brazilian Parents of Children with Autism Spectrum Disorders. Autism, 21, 603-610. https://doi.org/10.1177/1362361316677718

Benitez, P., \& Domeniconi, C. (2014). Training of Educational Agents: Proposal to Develop Inclusive Strategies. Revista Brasileira de Educação Especial, 30, 371-386. (In Portuguese) https://doi.org/10.1590/S1413-65382014000300005

Benitez, P., Gomes, M., Bondioli, R., \& Domeniconi, C. (2017). Mapping of Inclusive Strategies for Students with Intellectual Disabilities and Autismo. Psicologia em Estudo (Maringá), 22, 81-93. (In Portuguese) https://doi.org/10.4025/psicolestud.v22i1.34674

Cooper, J. O., Heron, T. E., \& Heward, W. L. (2007). Applied Behavior Analysis (2nd ed.). Upper Saddle River, NJ: Pearson Education.

Davis, F. D. (1989). Perceived Usefulness, Perceived Ease of Use, and User Acceptance of Information Technology. MIS Quarterly, 13, 319-340. https://doi.org/10.2307/249008

Foxx, R. M. (2008). Applied Behavior Analysis Treatment of Autism: The State of the Art. Child and Adolescent Psychiatric Clinics of North America, 17, 821-834. https://doi.org/10.1016/j.chc.2008.06.007

Girolametto, L., Sussman, F., \& Weitzman, E. (2007). Using Case Study Methods to Investigate the Effects of Interactive Intervention for Children with Autism Spectrum 
Disorders. Journal of Communication Disorders, 40, 470-492.

https://doi.org/10.1016/j.jcomdis.2006.11.001

Gomes, C. G. S., Souza, D. das G. de, Silveira, A. D., \& Oliveira, I. M. (2017). Early and Intensive Behavioral Intervention with Children with Autism through the Training of Caregivers. Revista Brasileira de Educação Especial, 23, 377-390. (In Portuguese) https://doi.org/10.1590/s1413-65382317000300005

Gortmaker, V. J., Daly III, E. J., McCurdy, M., Persampieri, M. J., \& Hergenrader, M. (2007). Improving Reading Outcomes for Children with Learning Disabilities: Using Brief Experimental Analysis to Develop Parent Tutoring Interventions. Journal of Applied Behavior Analysis, 40, 203-221. https://doi.org/10.1901/jaba.2007.105-05

Guimarães, M. S. S. (2018). Caregiver Training for Management of Inappropriate Behavior in Children with Autism Spectrum Disorder. Revista Brasileira de Terapia Comportamental e Cognitiva, 20, 40-53. (In Portuguese) https://doi.org/10.31505/rbtcc.v20i3.1217

Jacobson, J. W. (2000). Early Intensive Behavioral Intervention: Emergence of a Consumer-Driven Service Model. The Behavior Analyst, 23, 149-171. https://doi.org/10.1007/BF03392008

Johnson, E., \& Hastings, R. P. (2002). Facilitating Factors and Barriers to the Implementation of Intensive Home-Based Behavioural Intervention for Young Children with Autism. Child: Care, Health and Development, 28, 123-129. https://doi.org/10.1046/j.1365-2214.2002.00251.x

Kabout, S., Masi, W., \& Segal, M. (2003). Advances in the Diagnosis and Treatment of Autistic Spectrum Disorders. Professional Psychology: Research and Practice, 34, 26-33. https://doi.org/10.1037/0735-7028.34.1.26

Leach, D. (2014). Bringing ABA into Early Childhood Routines to Meet the Needs of Young Children with ASD. Journal of the American Academy of Special Education Professionals, 56-67. https://eric.ed.gov/?id=EJ1134766

Lovaas, O. I. (1987). Tratamiento conductual y funcionamiento educativo e intelectual normal en niños autistas. Journal of Consulting and Clinical Psychology, 55, 3-9. https://thelovaascenter.es/media/attachments/2017/03/08/article_87.pdf https://doi.org/10.1037//0022-006X.55.1.3

Mcconachie, H. et al. (2005). A Controlled Trial of a Training Course for Parents of Children with Suspected Autism Spectrum Disorder. The Journal of Pediatrics, 147, 335-340. https://doi.org/10.1016/j.jpeds.2005.03.056

Moore, T. R., \& Symons, F. J. (2009). Adherence to Behavioral and Medical Treatment Recommendations by Parents of Children with Autism Spectrum Disorders. Journal of Autism and Developmental Disorders, 39, 1173-1184.

https://doi.org/10.1007/s10803-009-0729-0

Nielsen, J. (1993). Usability Engineering. San Francisco, CA: Morgan Kaufmann Publishers.

Nielsen, J. (1994). Heuristic Evaluation. In J. Nielsen, \& R. L. Mack (Eds.), Usability Inspection Methods (pp. 25-62). New York: John Wiley \& Sons. http://dl.acm.org/citation.cfm?id=189200.189209

Norman, D. (1988). The Design of Everyday Things (No. 842). New York: Doubleday. http://books.google.com.br/books?id=b09jQgAACAAJ

Rodrigues, K. R. H., Viel, C. C., Zaine, I., da Cunha, B. C. R., Scalco, L., \& Pimentel, M. G. C. (2017). Data Collection and Customized Intervention as Interactive Multimedia Documents. In Proceedings of the 23nd Brazilian Symposium on Multimedia and the Web (pp. 57-60). New York: ACM. https://doi.org/10.1145/3126858.3131574 
Sallows, G. O., \& Graupner, T. D. (2005). Intensive Behavioral Treatment for Children with Autism: Four-Year Outcome and Predictors. American Journal on Mental Retardation, 11, 417-438.

https://doi.org/10.1352/0895-8017(2005)110[417:IBTFCW]2.0.CO;2

Sundberg, M. L. (2008). Verbal Behavior Milestones Assessment and Placement Program. Concord, CA: AVB. https://repositorio.ufscar.br/handle/ufscar/9315

Vollmer, T. R., Roane, H. S., Ringdahl, J. E., \& Marcus, B. A. (1999). Evaluating Treatment Challenges with Differential Reinforcement of Alternative Behavior. Journal of Applied Behavior Analysis, 32, 9-23. https://doi.org/10.1901/jaba.1999.32-9

Zaine, I., Rodrigues, K. R. H., da Cunha, B. C. R., Viel, C. C., Orlando, A. F., Machado Neto, O. J., Magagnatto, Y., \& Pimentel, M. G. C. (2016). ESPIM: An Ubiquitous Data Collection and Programmed Intervention System Using ESM and Mobile Devices. In Proceedings of the 22nd Brazilian Symposium on Multimedia and the Web (pp. 13-14) New York: ACM. https://doi.org/10.1145/2976796.2988222 